\title{
More than carbon price
}

\author{
In collaboration with experts in agroforestry, agricultural economics and policy, development \\ economist Utkur Djanibekov estimated the viability of small-scale Clean Development Mechanism \\ afforestation in Uzbekistan.
}

\begin{abstract}
What was the impetus for this project? What was the main objective of the work at the beginning of the project?

Irrigated agriculture in Central Asia, particularly in regions near the Aral Sea, faces a wide range of challenges, including land degradation and the impacts of climate change on water resources. As a result, vast areas of cropland generate little or no profit from cultivation. Agroforestry studies conducted in the Khorezm region of Uzbekistan revealed that afforestation with well-adapted tree species could increase the production potential of degraded lands. Our study examined the economic viability of afforestation on marginal croplands under the Clean Development Mechanism (CDM), and if it could improve rural livelihoods through the provision of non-timber tree products.
\end{abstract}

\section{How did you go about finding suitable collaborators?}

The Center for Development Research (ZEF) at the University of Bonn has long-standing research experience in the Khorezm region, and this is where I first met my collaborators in 2007 - at that time in the context of water-related studies. As a result, when

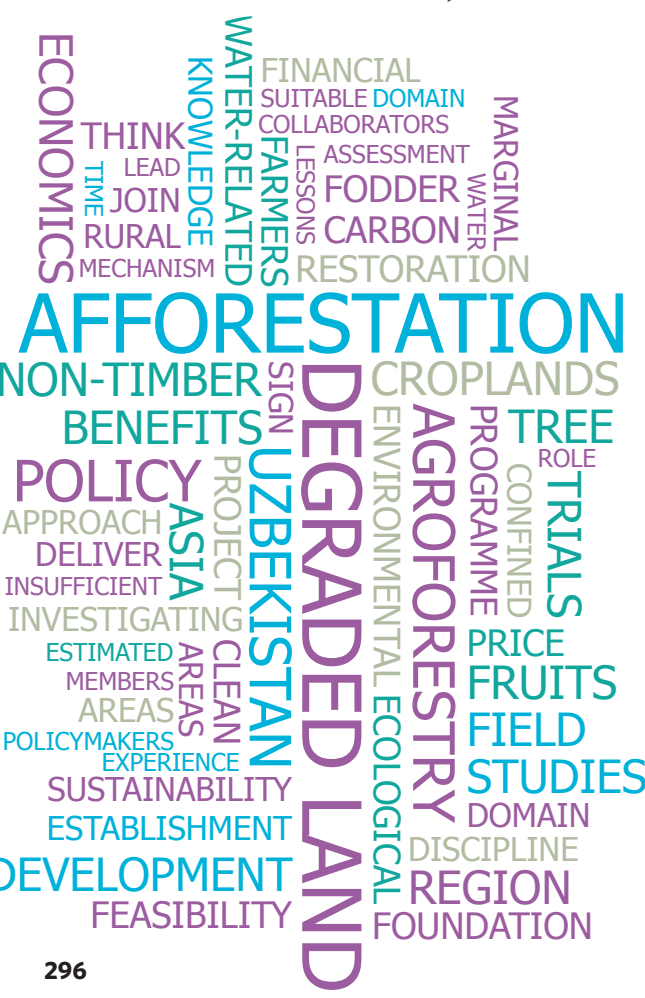

the agroforestry project commenced in Khorezm in 2009 by initiative of Asia Khamzina, an expert in the field based at ZEF, I joined the group. Together, we integrated the results of the afforestation field trials into the economic assessment.

Did you encounter any difficulties in working with a team of experts with different research backgrounds? I didn't find any difficulty. It was and continues to be an enjoyable experience. The world is a complex system, and I think that in climate change-related research it is important to look at the problems from different perspectives beyond one's own discipline.

What was the highlight of working with an interdisciplinary team?

The highlight to me was certainly the fact that each team member could explore and contribute to each other's disciplines. We each benefited from the expertise of the other members to achieve a much deeper and thorough understanding of the issues related to afforestation in the irrigated drylands. I enjoyed being engaged in innovative research on the rehabilitation of degraded croplands through afforestation and observing the fieldwork of my colleagues establishing afforestation trials on highly salinized soils. The interviews with local farmers and policymakers allowed us to understand the local perceptions and preferences for developing relevant policies to integrate trees in the agricultural landscape.

\section{Any surprises?}

We were surprised to find out that the average price of sequestered carbon under the CDM mechanism cannot compensate alone for the initial investments of short-term afforestation projects under the current climate change agenda. Yet, such projects could generate high returns from non-timber products (fruits, leaves as fodder, and fuel-wood) and environmental services (land improvement and water saving). Integrating these benefits in short-term CDM afforestation projects could potentially increase their economic feasibility. We were also surprised to find out that even when aware of the monetary and environmental benefits of afforestation, some of the interviewed farmers were still not practicing this option - a sign that adequate policy support is needed.

\section{Did you learn any lessons about} interdisciplinary collaboration from this project that would benefit others trying to do similar work?

An initial discussion within the team is essential to define the framework of the study and identify what can be taken from each field of knowledge. This discussion needs to continue during the development of the study, but it is essential to have it from the outset. When a potentially complex problem is identified from one specific angle, the tendency is to address it from one domain only. A single-expertise approach could be insufficient to cover all multidimensional aspects of a problem, and may deliver an incomplete research output. In contrast, an interdisciplinary approach would lead to a broad assessment and deliver relevant results both scientifically and practically.

\section{Where did the financial support come from? \\ We highly appreciate the role of the} Robert Bosch Foundation, which supports research in various fields of sustainability science. The foundation made possible the establishment of the agroforestry working group through the programme on sustainable use of renewable natural resources. I also received the support from the International Postgraduate Studies in Water Technologies scholarship programme.

\section{Any final thoughts?}

When investigating the feasibility of tools for climate change mitigation, ecological restoration and economic development, researchers cannot remain confined to their own specialism. Experts need the ability to think outside the box and look at the broader picture. This is how they can ensure that their work is relevant and beneficial to people.

\section{INTERVIEW BY MONICA CONTESTABILE}

This Beyond Boundaries is based on the work by Utkur Djanibekov and colleagues, published in Forest Policy Econ. http://dx.doi. org/10.1016/j.forpol.2012.01.006 (2012). 